\title{
Damage identification in beams using additional rove mass and wavelet transform
}

\author{
Erwin U. L. Palechor \\ Department of Civil Engineering, University of Cariri Ciudade Universitária, Juazeiro do Norte-CE, Brazil \\ erwin.lopez@ufca.edu.br
}

Luciano M. Bezerra

Department of Civil Engineering, University of Brasilia Campus Darcy Ribeiro SG-12 Brasilia, Distrito Federal, Brazil lmbz@unb.br

Marcus V. G. de Morais

Department of Mechanical Engineering, University of Brasilia, Campus Darcy Ribeiro, Brasilia, Distrito Federal, Brazil mvmorais@unb.br

Ramon S. Y. R. C. Silva

Department of Civil Engineering, University of Brasilia Campus Darcy Ribeiro SG-12 Brasilia, Distrito Federal, Brazil ramon@unb.br

\section{Edenia N. Barros}

Department of Civil Engineering, University of Cariri Ciudade Universitária, Juazeiro do Norte-CE, Brazil edenia.barros@ufca.edu.br

\begin{abstract}
There is a need for efficient techniques that could identify damages in structures such as in bridges, pipelines, buildings, dams, among others. In order to carry out continuous monitoring of structures, this paper proposes a new experimental methodology for the identification of damages in steel beams. The methodology is based on the variation of the fundamental frequencies caused by the application of an extra additional mass along the length of the structure. This paper proposes the association of additional masses with wavelet transform in the processing of non-stationary signals and the realization of experimental tests on commercial profiles of steel beams under support conditions close to real situations. The experimental tests of simply supported steel beams are presented and discussed in this paper. The results show that the proposed methodology can identify damages or at least give a good indication of the region where damages might be.
\end{abstract}

KEYWORDS. Damage; Frequencies; Wavelets; Steel I beam.

\section{open ACCESS}

Citation: Palechor, E.Y.L., Bezerra, L.M., de Morais, M. V. G., Silva, R.S.Y.R.C., Barros, E.N., Damage identification in beams using additional rove mass and wavelet transform, Frattura ed Integrità Strutturale, 49 (2019) 614-629.

Received: 06.02.2019

Accepted: 05.05.2019

Published: 01.07.2019

Copyright: (C) 2019 This is an open access article under the terms of the CC-BY 4.0, which permits unrestricted use, distribution, and reproduction in any medium, provided the original author and source are credited. 


\section{INTRODUCTION}

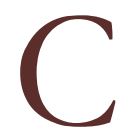

racks often occur in structural members and cause serious structural pathologies or even structural collapse. The effects of these damages influence the dynamic response (frequencies and mode shapes) of structural systems. Structural damages must be identified in its initial state before compromising the integrity and service life of the structure. However, in its initial state, a crack is relatively small making it difficult to detect changes in the dynamic properties. Moreover, there are situations where damages may be hidden due to external cover façade, finishing, or skinning of buildings, bridges, etc... turning the detection of damages a difficult process. Therefore auxiliary tools to indicate possible existence of damages are always welcome.

One of the first concepts of structural identification was introduced in Civil Engineering almost two decades ago by Aktan et al [1]. However, methods for identifying cracks, based on the changes of dynamic properties of bridges and buildings, are not very well effective and practical. Moreover, depending on the size of the surface crack, a crack can be detected using traditional technique like the visual inspection. However, it is not possible to visually identify cracks when the structure surface is covered, insulated or located in unreachable locations. To overcome these difficulties, numerical/computational techniques have been under development [2,3], thus enabling quick decision-making process concerning the minimization or elimination of damages.

From the point of view of safety and economy, the detection of damages especially in bridges is an important issue. It is essential to perform periodic inspection to detect changes in the structural stability [4]. A recent research on the technical literature shows that many damage identification algorithms were developed using dynamic characteristics, especially in the frequency domain [5]. In general these techniques uses comparisons between the intact and damaged response of the structure. Techniques based on Wavelet Transforms can overcome this limitation. Such techniques have been applied over the years and have been presented satisfactory results $[6,7,8,9,10,11,12]$. However, the purpose of this paper is to use additional masses associated with wavelet transform in the processing of non-stationary signals and apply this methodology in experimental done in commercial profiles of steel beams under support conditions close to real situations.

\section{USE OF ADDITIONAL MASSES}

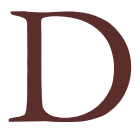

amage identification may be seen as an inverse problem of identification of a system whose input signals and output signals are known, but the geometry of the damage location and shape are unknown [13]. This means that the purpose of damage detection is to describe a damage in an existing structural model, based on output data obtained experimentally (dynamic response) from specific input signals. It is often desirable to detect irregularities or changes in structure response, considering properties that have been altered by the presence of the damage in the structure. This work presents the application of an identification methodology based on the analysis of the dynamic properties of simply supported steel beams. Beams here are submitted to the action of additional masses that can generate progressive changes of the natural frequencies $[14,15]$. The change in the structural stiffness due to the existence of damage in the beam may not be so evident. Therefore, in this research, the Wavelet Transform is used to help in the process of locating possible stiffness changes due to damages $[16,17,18]$. This research also presents experimental tests results on steel beams with simulated damages. The experimental tests were carried out in the Laboratory of Vibrations of the Department of Mechanical Engineering in the University of Brasilia. Even though the experiments were conducted within the laboratory, the size of the beams tested corresponds to small commercialized steel beams available in the market.

In this research, the natural frequencies, which act as sensitive indicators of the structural integrity were chosen as a measurement parameter of the dynamic properties of the structure. In this way, frequent inspections and measurement of the first frequency may be used to monitor the integrity state of the structure. The first frequency variation signals due to an additional mass at different locations may be processed with Wavelet Transform and may indicate the region where damages may be found [16]. Therefore, this paper presents a new methodology based on the measurements of just the fundamental frequency of a vibrating structure (in this research: beams) with an added mass positioned at different locations along the beam. Damage can be detected observing the peaks of the Discrete Wavelet Transformation of the signal of the variation of the fundamental frequency (DWT-f1) vs. Added Mass Positions (AMP). Two steel beams, or specimens, with different lengths and a variety of simulated damages are tested and the proposed methodology applied. Tab. 1 presents the geometric characteristics of the specimens.

The additional mass placed on the beams were small steel plates fixed with braces and bolts. The assembly of the added masses is schematically shown in Fig. 1. 


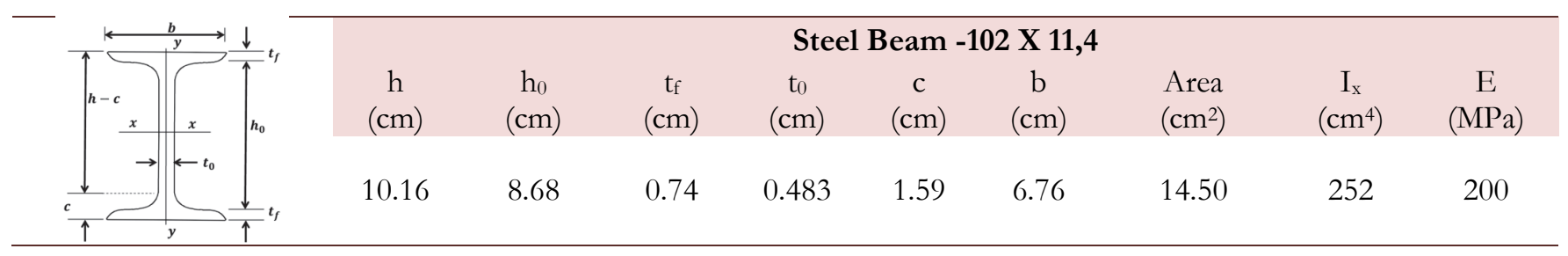

Table 1: Geometric and beam characteristics nominal values.

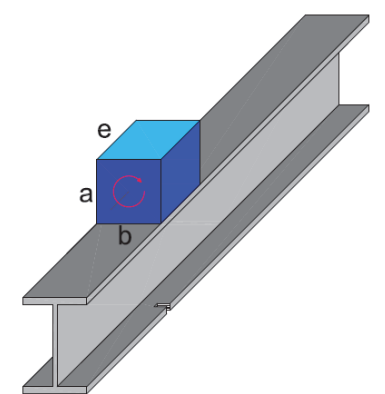

(a) Additional Mass

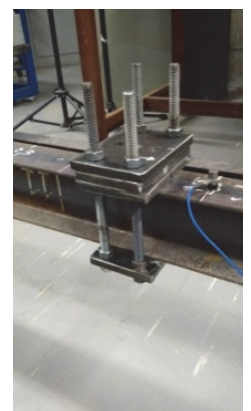

(b) Additional Mass

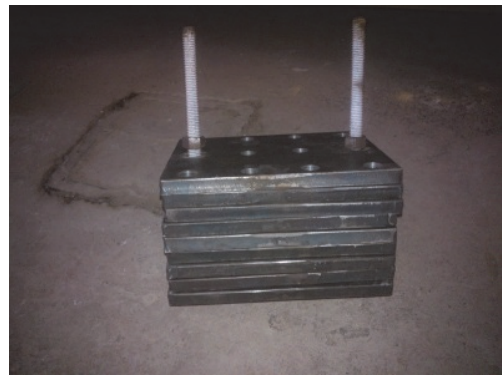

(c) Steel plate to add mass.

Figure 1: Additional mass on the beam.

The additional mass system allows the fixing of a different weights depending on the number of steel plates used. Additional masses are adequately positioned at nodes previously defined in the discretization. The steel plate must be tight to fixation avoid inappropriate movements and trepidations of the added masses that could influence the results.

\section{EXPERIMENTAL TESTS CHARACTERISTICS}

\section{Location of damages}

T $\mathrm{n}$ the following beam specimens, induced damages simulate the effect of beam cross section deteriorations. It is known that fatigue or corrosion deteriorations are rough processes with resulting irregular loss of cross section. In the experimental tests, deteriorations are ideally thought of to be equivalent to damages caused by fatigue deterioration or corrosion of beams [8]. A set of one or more cracks is considered to be a damage. In practice, the simulated damage may be thought of as an equivalent deterioration of the steel beam cross section.

Such damages were made with a circular saw of $3 \mathrm{~mm}$ thick (Fig. 2). The depth and width of the cuts were made according to the damage cases set forth in Figs. 3 and 4.

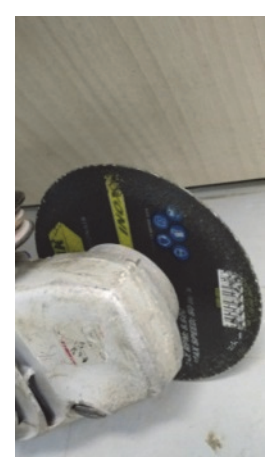

a) Circular saw

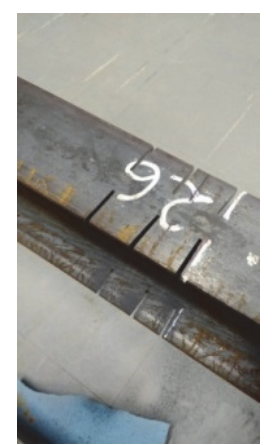

b) Damage-1:Three-notches

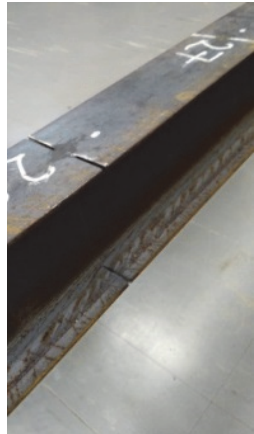

c) Damage-2:one-notch

Figure 2: Damage simulations, a) Circular saw, b) Damage-1, c) Damage-2. 

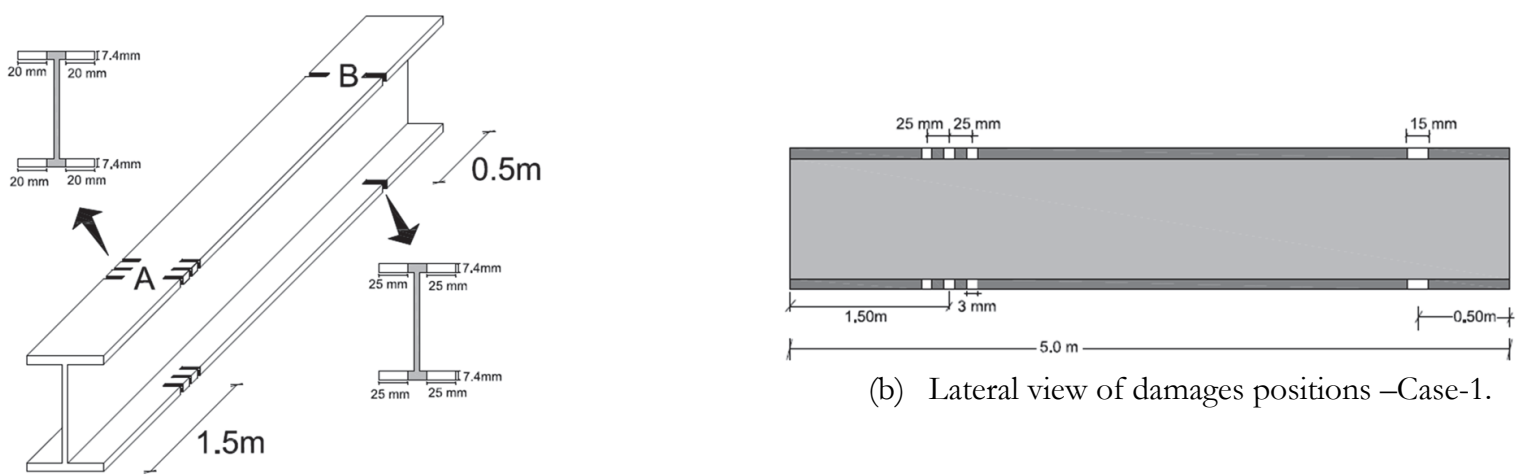

(b) Lateral view of damages positions -Case-1.

(a) Perspective view of damage positions - Case-1.

Figure 3: Geometry and position of damages for the beam with $5 \mathrm{~m}$ span.
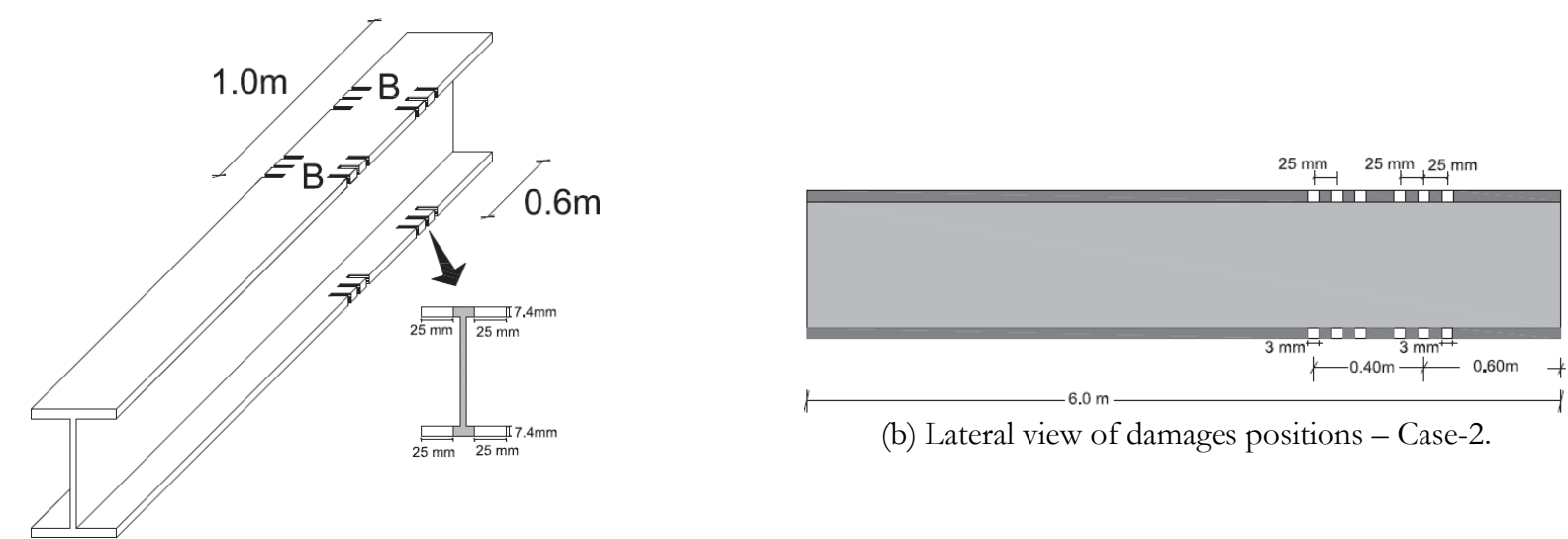

(b) Lateral view of damages positions - Case-2.

(a) Perspective view of damage positions -Case-2.

Figure 4: Geometry and location of damages for the beam with $6 \mathrm{~m}$ span.

The two proposed cases in this paper correspond to beams with different damage positions in beams with spans of $5 \mathrm{~m}$ and $6 \mathrm{~m}$. The simulated damages are notches symmetrical placed with respect to the steel beam web, and located in the upper and lower flanges of the beams.

Case-1: Figs. 3 and 5 show this case, the numbers in Fig. 5 over the Beam-1 and outside it are, respectively, elements and nodes. The beam span is $5 \mathrm{~m}$, Damage- 1 is located at $1.5 \mathrm{~m}$ to the left support, between nodes 8 and 9 . The notches are spaced every $2.5 \mathrm{~cm}$. The position of the second damage, Damage-2 is a notch located at $4.5 \mathrm{~m}$ (between nodes 23 and 24 ) with respect to the same support (Fig. 5). The position of the two damage generated a decrease in the moment of inertia of the cross section ( $\mathrm{Ix}$ ) of $52.2 \%$ and $65.6 \%$, respectively.

Case-2: length of Beam-2 is $6 \mathrm{~m}$ and the Damage- 1 is located $5 \mathrm{~m}$ (nodes 26 ) from the left support, spaced every $2.5 \mathrm{~cm}$. Damage-2 is a notch located at $5.4 \mathrm{~m}$ (node 28) in relation to the same support (Fig. 6). The position of the two damage generated a decrease in the moment of inertia of the cross section (Ix) of $65.6 \%$.

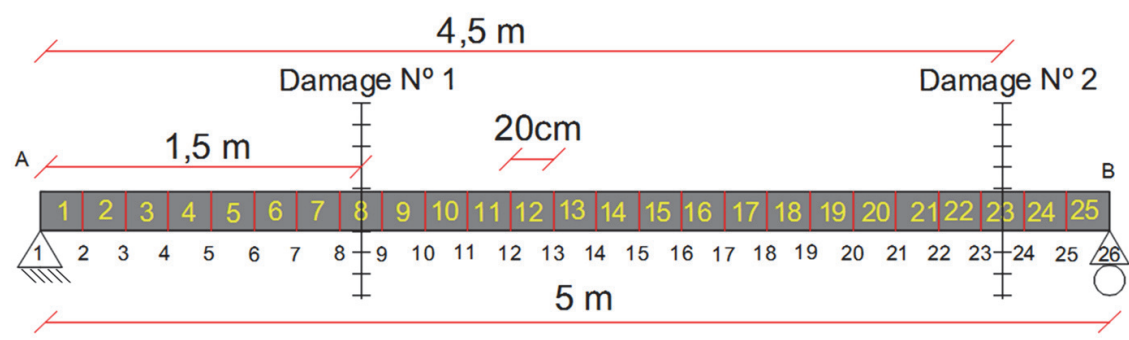

Figure 5: Damage positions in Case 1. 


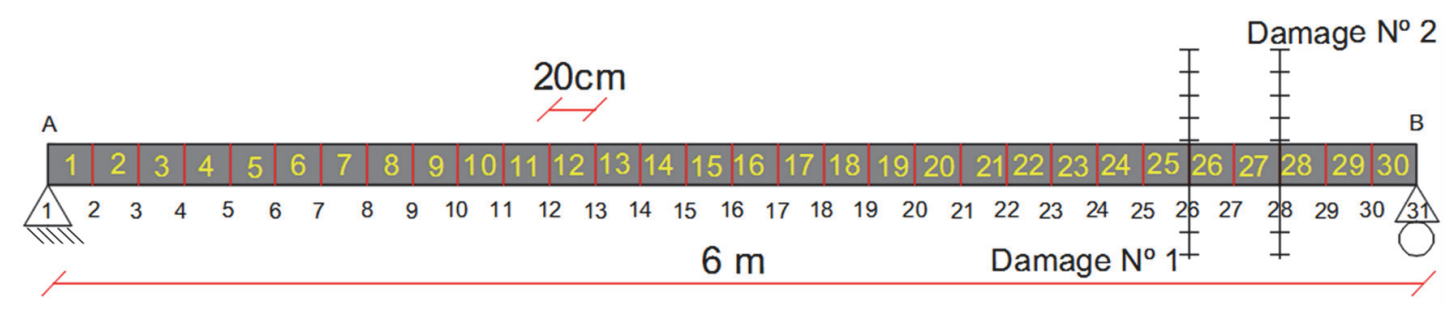

Figure 6: Damage positions in Case 2.

The additional masses (M) add together $3.366 \mathrm{~kg}$ for Case-1 and $24.718 \mathrm{~kg}$ for Case-2.

\section{Supports}

The two beam specimens (Figs. 3 and 4) are simply supported. For that, the left and right ends of the beam are supported by two steel rollers held over thick steel plates. The right steel plate is plain, but the left steel plate has a notch to accommodate the steel roller. Details of these two supports can be seen in Figs. 7a and 7b. Observing these figures, the right support constraints displacements in $\mathrm{X}$ and $\mathrm{Y}$ directions and allows free translation in the Z-direction and the $\mathrm{X}$-axis. The left support allows no translation just rotation around the $\mathrm{X}$-axis.

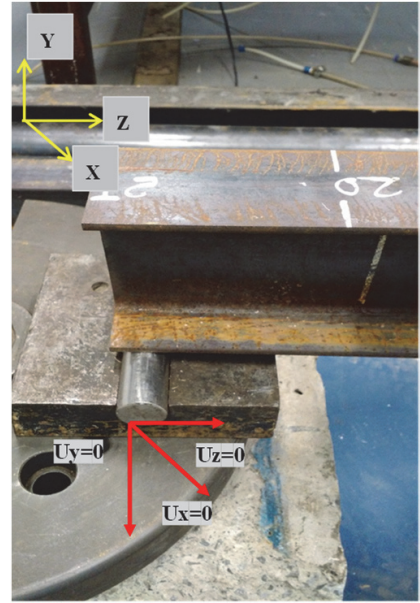

(a) Left Support.

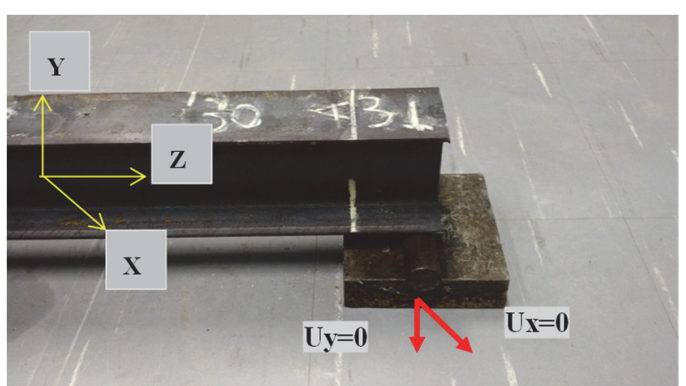

(b) Right support.

Figure 7: Detail for the simple supports at beam ends.

It is important to emphasize that the supports constitute a fundamental part of the structure, restricting the degrees of freedom necessary for the stability of the beam. In this research, the two supports are fundamental for the process of damage identification, due to the influence of residual noise signals generated at the supports at the ends of the beam specimens. Such noises are caused by friction between the roller and the beam despite lubrification. The roller surfaces at the supports are kept at the same condition to avoid extra unknown noise sources [19].

\section{Instrumentation}

In order to carry out the dynamic tests the following tools are used:

- Signal Conditioner (Fig. 9a);

- Accelerometer model 352C34 (Fig. 8a)

- Accelerometer model 352C33 (Fig. 8b);

- Instrumented hammer PCB model 086C0, with steel tip (Fig. 9b).

- Computer with Lab-View software for data acquisition

Fig. 10 shows details of the test scheme assemblage the steel beams in the Laboratory of Vibration and Dynamics of Systems of the University of Brasilia.

For the tests, two accelerometers are used, one of the accelerometers is located in the middle of the span (L / 2) and the second accelerometer is located at L / 4. (Fig. 11). 


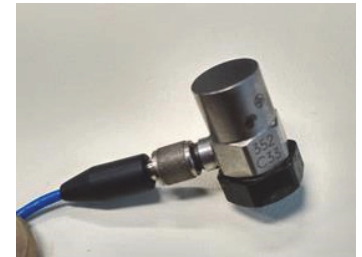

a) Accelerometer C33.

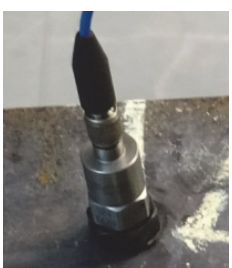

b) Accelerometer C34.

Figure 8: Instrumentation of the test, a) Accelerometer C33, b) Accelerometer C34.

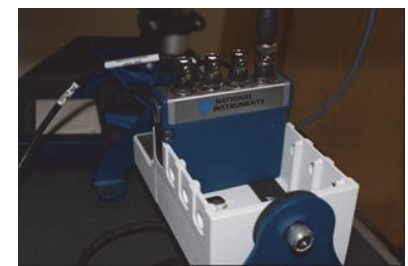

a) Signal conditioner.

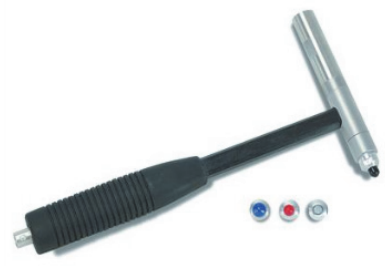

b) Impact hammer.

Figure 9: Instrumentation of the test, a) Signal conditioner, b) Impact hammer.

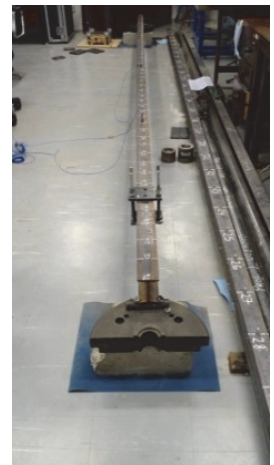

a) Simply supported beam.

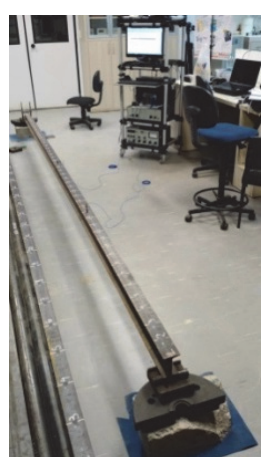

b) Data acquisition system.

Figure 10: General view of the test system, a) Simply supported beam, b) Data acquisition system.

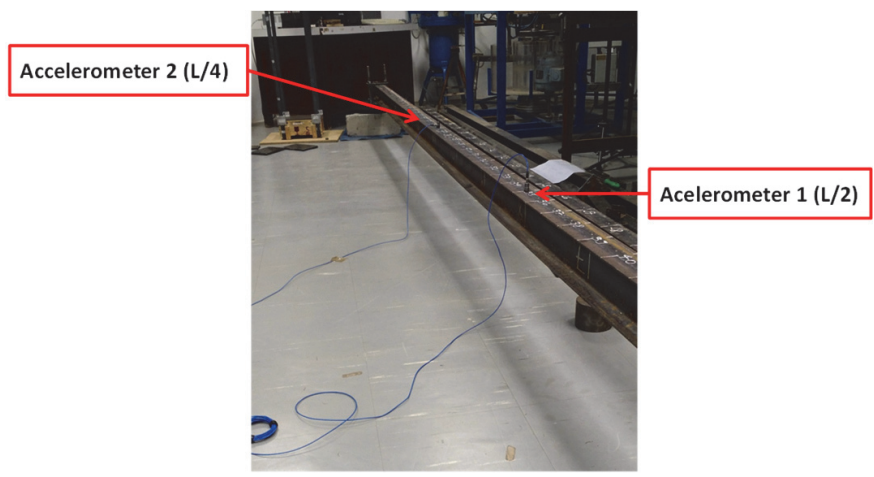

Figure 11: Position of the accelerometers.

Discretization of the beam

The discretization of the beam is important for the positioning control of the additional mass along the beam. A spacing "s" of $20 \mathrm{~cm}$ for both Cases (Case-1 and Case-2), as can be seen in Fig. 12 is considered. 


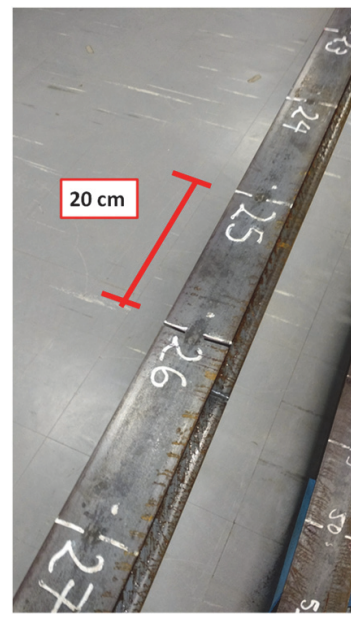

Figure 12: Discretization ( $\mathrm{s}=20 \mathrm{~cm}$ elements) of the beam - Experimental tests.

Using a spacing "s", the span length " $\mathrm{L}$ " can have $(\mathrm{L} / \mathrm{s})$ elements and $(\mathrm{L} / \mathrm{s}+1)$ nodes. Therefore, for $\mathrm{L}=5 \mathrm{~m}$, and $\mathrm{L}=6 \mathrm{~m}$, and $\mathrm{s}=20 \mathrm{~cm}$, one can generated 26 nodes and 31 nodes for the positioning of the added mass, respectively for Beam-1 (5m) and Beam-2 (6m).

\section{EXPERIMENTAL PROCEDURE}

0 tep 1: for the model developed in this research, the beam specimens were subjected to impact load produced by Impact Hammer with a force of approximately $400 \mathrm{~N}$, applied in the central region near the middle of the beam span - as can be observed in Figure 13.

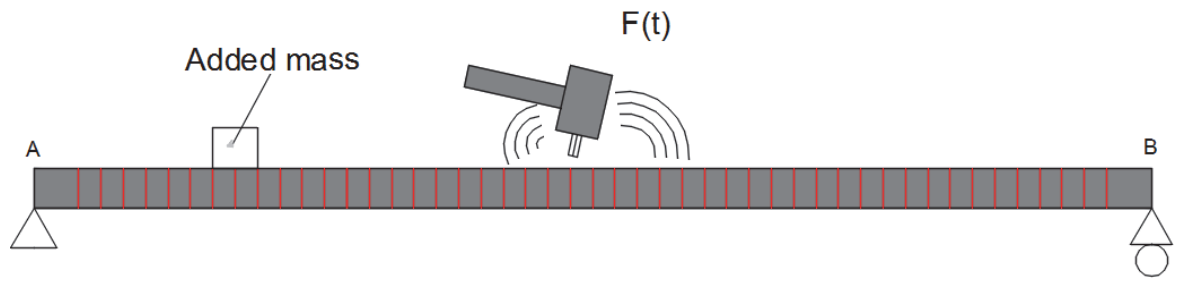

Figure 13: Excitation force fort the numerical analyses.

Step 2: the force and acceleration dynamic signals was acquired by signal conditioner connected to an impact hammer and two accelerometers. The Fig. 14 show programming of acquisition and signal pre-visualization. The acquisition system LabView provide the real time visual of dynamic signals. It was important to avoid double peaks by erroneous impact test. Step 3: the modal impact test was carried out with four repetitions. To reduce the leakage effect, exponential and force windows was applied to acceleration and force signal respectively. The auto-spectrum of dynamic force shows a signal constant $(+-3 \mathrm{~dB})$ to frequency range choice.

Step 4: with an impact hammer test done, the force and acceleration dynamic signals were saved in a hard-disk to be later on treated by a MatLab script to obtain de Frequency Response Function (FRF) between force excitation and accelerometer measurement. Using a resolution greater than that given by Fast Fourier Transform (FFT) and performing a weighted average of the frequencies around a peak detected in the spectrum frequency, the first frequencies were accurately identified.

\section{Characteristics and calibration of parameters}

The frequency resolution is very important considering that there are frequency variations due to the additional mass. Thus, in this research, several configurations for the acquisition or analysis time after excitation ( $\mathrm{t}$ ), number of analyzed data $(\mathrm{N})$, acquisition rate $(\Delta \mathrm{t})$ and sampling frequency (Fs) are tested. Due to space reasons, it is impossible to present all the results attained. However, the best results were obtained with the following parameters: (a) Fs=1653 Hz, (b) $\mathrm{t}=9.9 \mathrm{~s}$, (c) $\Delta \mathrm{t}$ $=0.000605 \mathrm{~s}$, and $(\mathrm{d}) \mathrm{N}=16384\left(2^{14}\right)$. 


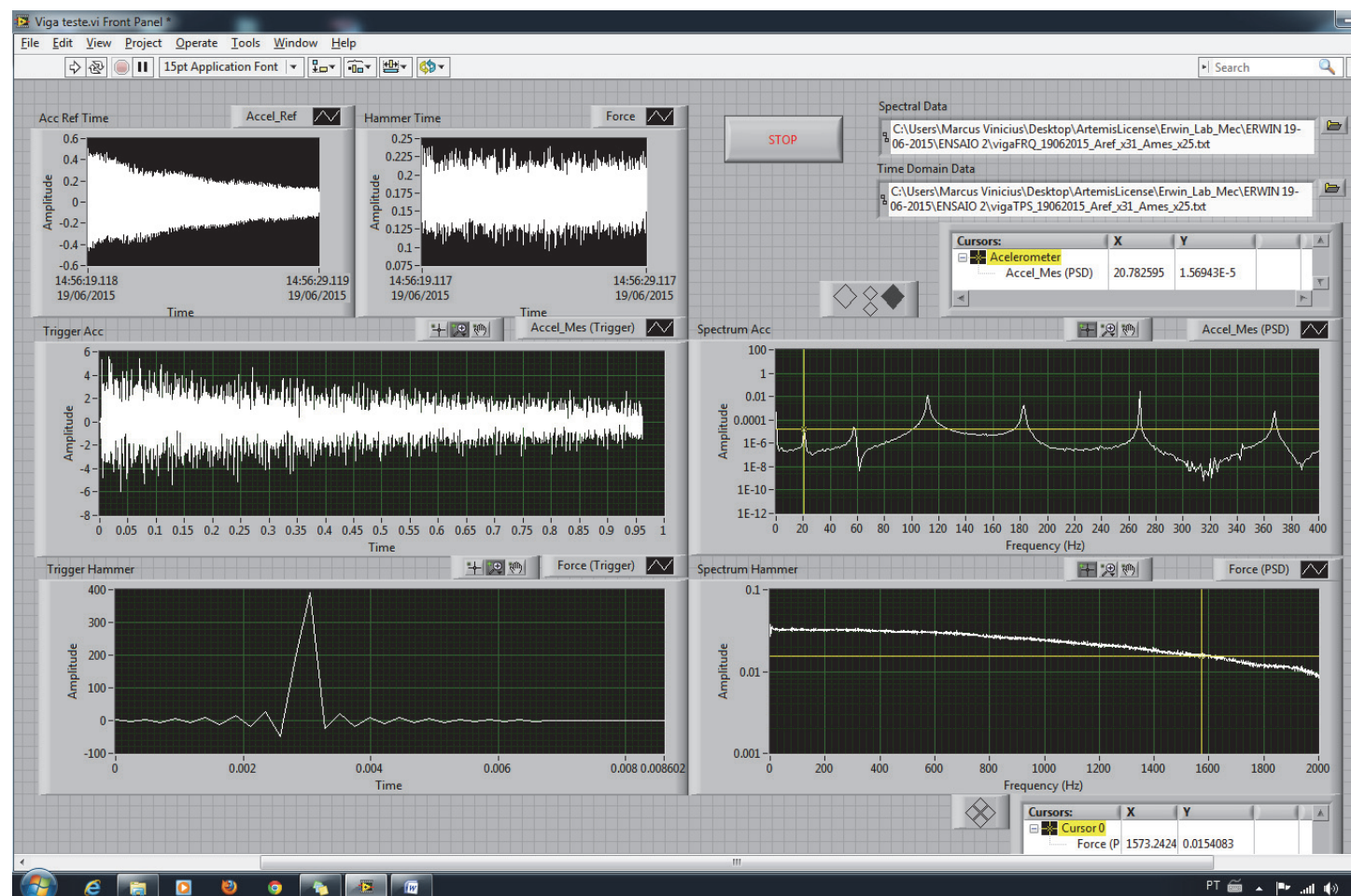

Figure 14: LabView control panel.

The flowchart of the methodology validation

The following flowcharts presents a scheme for the validation of the proposed damage identification method - see Fig. 15:

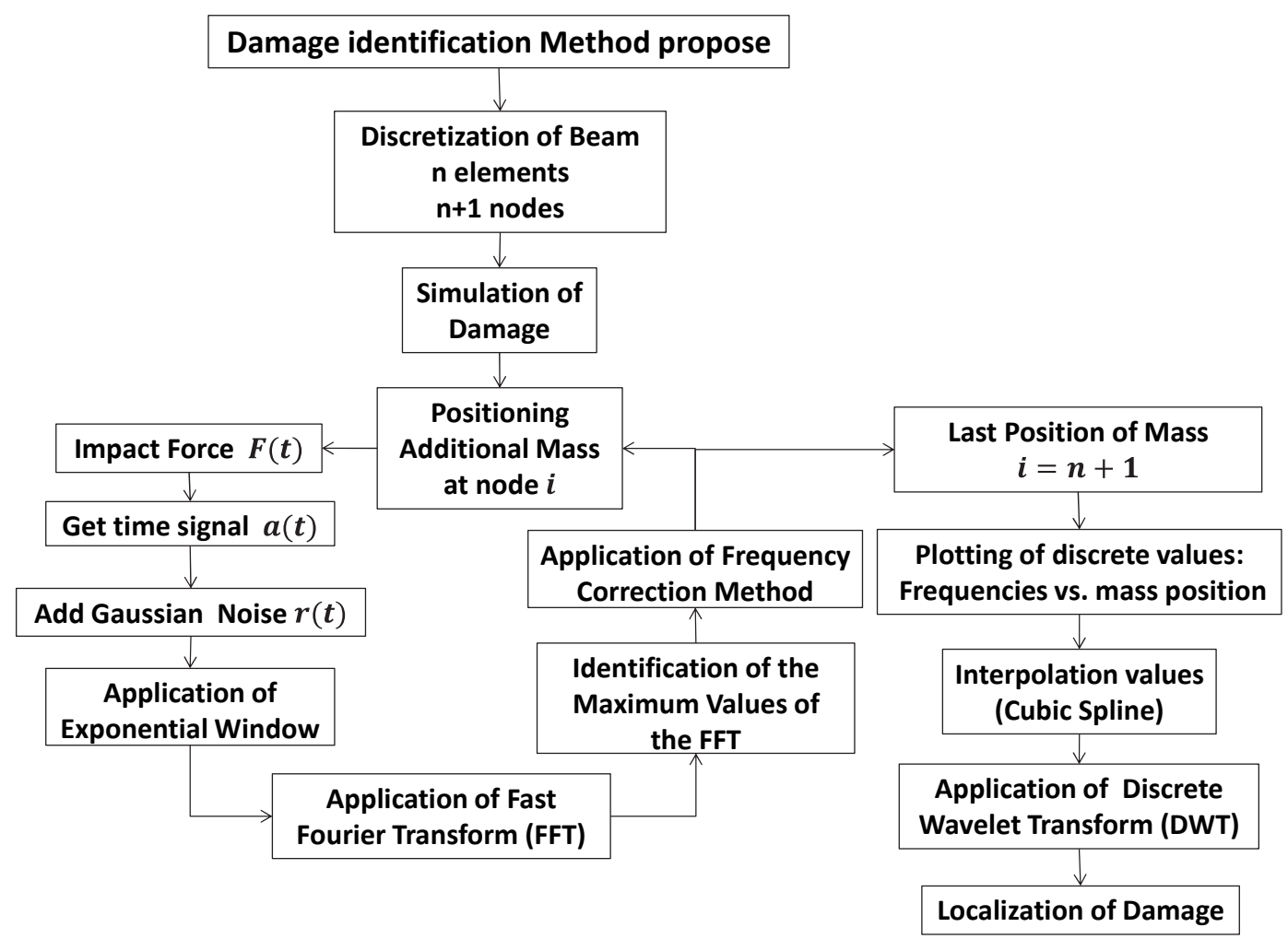

Figure 15: Flow chart of the methodology proposed. 


\section{SIGNAL TREATMENT}

$\mathrm{T}$ he division of the beam in elements, and nodes spaced by $20 \mathrm{~cm}$, generated, for the respective beams $(5 \mathrm{~m}$ and $6 \mathrm{~m}$ long), 26 and 31 positions for the added mass. After obtaining these 26 and 31 acceleration spectra ${ }^{*}$ ( $(t)$ for Case-1 and Case-2, respectively (corresponding to different positions of the added masses on the nodes defined in the discretization) a technique of Time Signaling was applied to each of the positioning of the added mass. This simple technique can improve signal characteristics and reduce effects such as the inherent noise of electronic equipment or the spectral leakage effect [12]. There are several types of window functions that can be applied depending on the signal. Each window function has its own characteristics for different applications.

In this research, several window functions were tested, initially the Hanning window, used for stationary signals [20], but because the signal generated in the impact test (transient) was non-stationary, the use of the exponential window (in Fig. 16) was chosen. For such a window, a better result is expected as the time signal treated is a non-permanent signal with decay due to the damping of the structure [21]. The Hanning and Hammimg windows were tested, but did not present good results, due to the influence of the null values at the beginning and at the end of the signal after the Windowing. Our analyses concluded that the exponential window with a decay coefficient $\mathrm{f}=1 \mathrm{e}-6$, is the one that best suits our methodology, showing the damping decay of the beam as in Fig. 16. The shape of this window is that of an exponential function, and such function can be mathematically expressed by Eqn. (1) [22]:

$$
w[n]=e^{\left(\frac{n \ln f}{N-1}\right)}, n=0,1,2, \ldots, N-1
$$

where: $\mathrm{N}=$ window size; and $\mathrm{f}=$ final value of exponent.

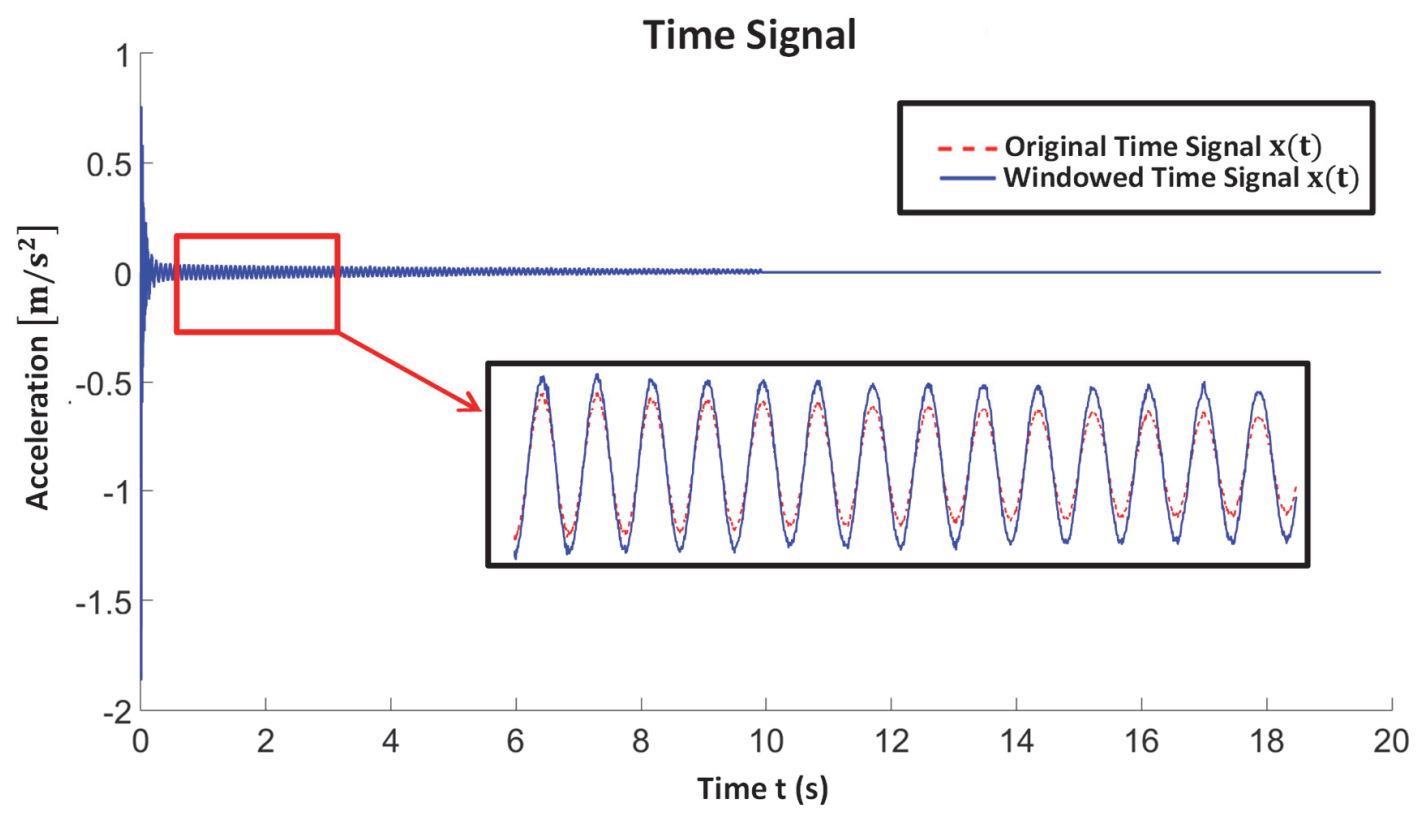

Figure 16: Acceleration $(\mathrm{x}(\mathrm{t}))$ vs. Time ( $\mathrm{t}$.

A technique used to interpolate the signal in the frequency domain consists of increasing the time signal $x^{\prime \prime}(t)$ with a vector of zeros, which generated a decrease of the intervals $(\Delta \mathrm{f})$ in the spectrum frequency. To perform this interpolation, the vector size is considered as a power of $2(2 \mathrm{n}$, and $\mathrm{n}=1,2,3, \ldots)$. In this case, the experimental acceleration vector has a 214 elements; and zeros are added to the end of the vector, increasing the size to 219. This increase in the data number $(\mathrm{N})$ in the FFT (or Fast Fourier Transform) generates a closer frequency range $(\Delta \mathrm{f})$. In this way a greater number of spectral lines is produced within the main lobe, making easier the approximation of the real frequency of the beam (Figs. 17 and 18). 


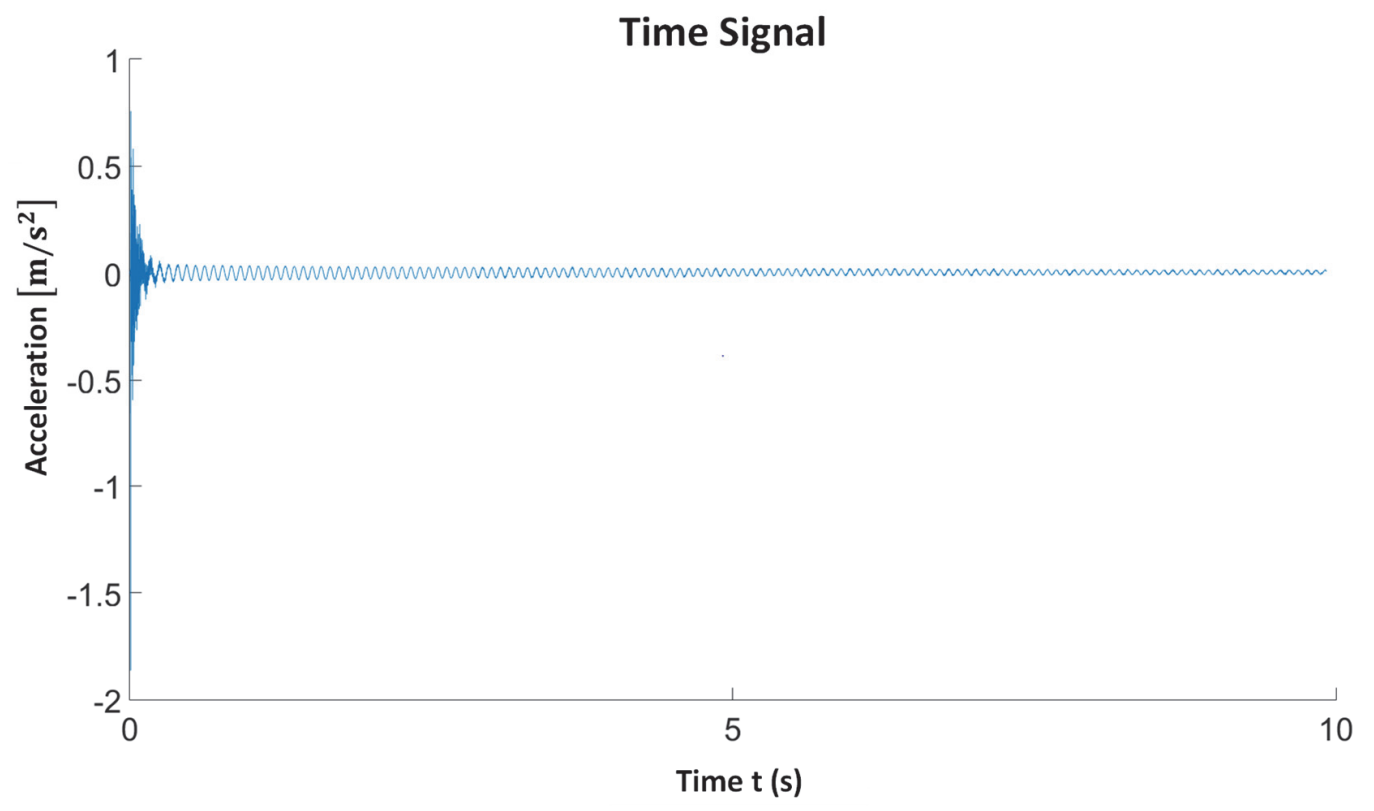

Figure 17: Spectrum of accelerations.

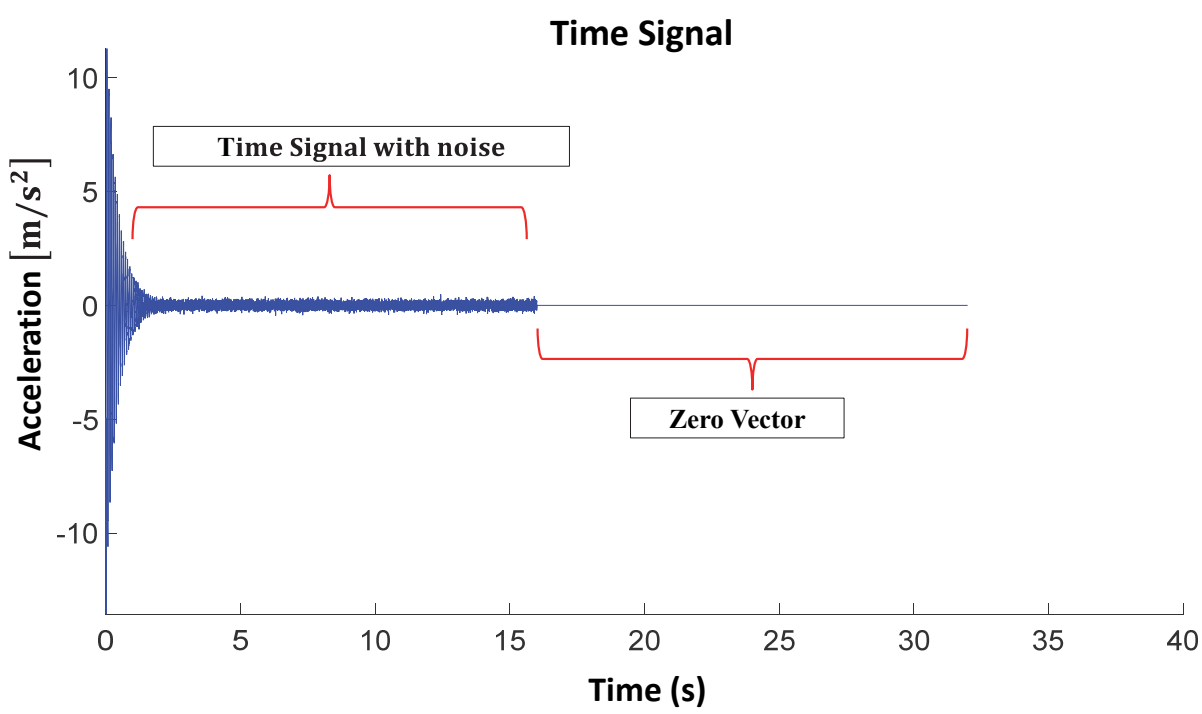

Figure 18: Spectrum of accelerations after interpolation.

In other words, the technique of signal interpolation in the frequency domain is very effective and practical because it does not add noise to the signal. In this way generating a decrease in the frequency ranges and a better approximation of the actual frequency of the structure can be achieved.

After the exponential window was applied to the time signals $x(t)$, the FFT was calculated. In the frequency domain, the peaks corresponding to the first natural frequency of the structure are identified. Fig. 19 shows the spectrum of frequencies windowed with the spectrum frequency without the application of the exponential window. Noise reduction and signal stabilization are clearly visible due to the use of the exponential window. 


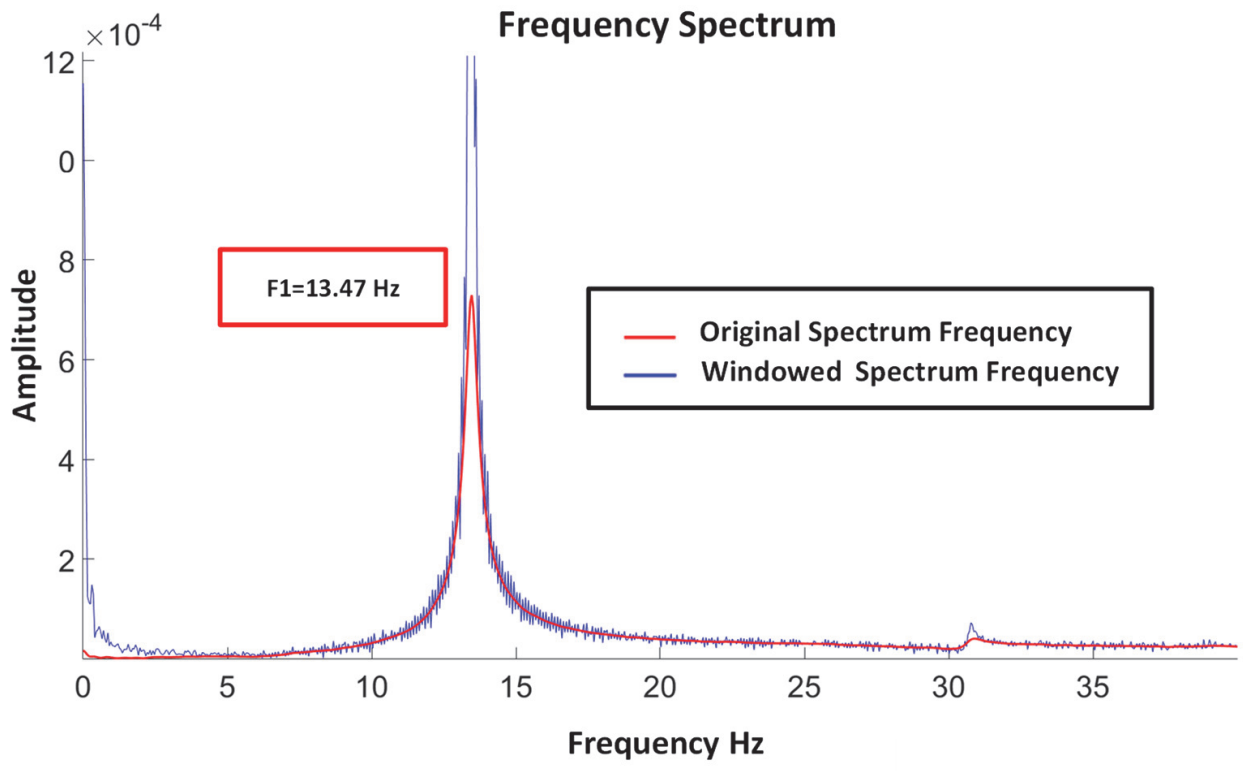

Figure 19: Spectrum Frequency.

After the identification of the first frequency peak, a method was applied to correct the main lobe. This method is essentially based on data from spectral lines that are around the frequency peak and perform a more detailed approximation of the maximum value that lobe reaches. Consequently, a better resulting in a greater approximation of the true frequency of the structure is obtained. This is a very important step in this research, due to the small variation in the frequency generated by the additional mass and the decrease of the stiffness in the damaged places [23]. Thus, the frequency value can be determined for a resolution greater than that given by the FFT, performing a weighted average of the frequencies around a peak detected in the spectrum frequency (Eqn. (2)) [24].

$$
\text { Estimated Frequency }=\frac{\sum_{i=j-m}^{j+m} \operatorname{Power}(i) i \Delta f}{\sum_{i=j-m}^{j+m} \operatorname{Power}(i)} \quad \Delta f=\frac{f_{s}}{N}
$$

where: $j$ is the frequency peak.

Power (i) represents the value of the amplitude of the spectral line after the application of the FRF. Once the corrected frequencies are obtained, these values are plotted and interpolated, to obtain a vector with a larger number of data and thus calculate the wavelet coefficients.

\section{DisCRETE WAVELET TRANSFORM.}

$\mathrm{W}$ avelets have been widely used to analyze time domain signals. For Wavelet analysis of spatial domain signals, we can simply substitute time for a spatial coordinate " $x$ ". Therefore $f(x)$ is the function to be used in the wavelet transform. The function $\mathrm{f}(\mathrm{x})$ may be modes of vibration or displacements due to static load [25]. Similar to the

Fast Fourier Transform (FFT) for windows, the one-dimensional Wavelet Transform projects a signal into a twodimensional space. The Wavelet Transform of the signal $\mathrm{f}(\mathrm{x})$ can be, mathematically, defined as [26]:

$$
W_{\psi}^{f}(a, b)=|a|^{-1 / 2} \int_{-\infty}^{\infty} f(x) \psi^{*}\left(\frac{x-b}{a}\right) d x
$$

where $\psi^{*}($.$) indicates the complex conjugate of \psi($.$) .$

It is also assumed that the mean value of the function $\psi(\mathrm{x})$ disappears: 


$$
\int_{-\infty}^{\infty} \psi(x) d x=0
$$

In the Wavelet transform, the signal $\mathrm{f}(\mathrm{x})$ is weighted by a function of variable " $\mathrm{x}$ ". The respective function is given by [25]:

$$
\psi^{a, b}(x)=|a|^{-1 / 2} \psi^{*}\left(\frac{x-b}{a}\right)
$$

The functions $\psi^{\mathrm{a}, \mathrm{b}}(\mathrm{x})$ are called wavelets or mother wavelet functions. The functions of the Fourier transform by windows usually oscillate and decay rapidly. In contrast to the functions $\psi^{\mathrm{a}, \mathrm{b}}(\mathrm{x})$, the number of oscillations remains constant with window changing. This means that a wavelet is "stretched" or "dilated" along the space represented by the vales of $\mathrm{x}$ along the x-axis. For Fourier transform (FT) with windows, the window size remains constant while the number of oscillations changes. This principle is illustrated in Fig. 20.
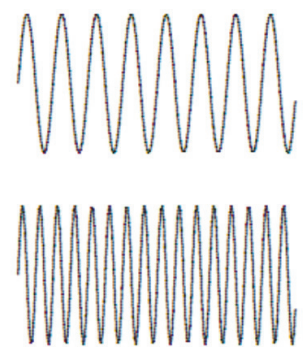

(a) FT Functions
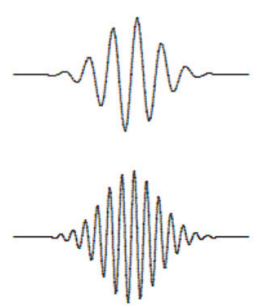

(b) FT Windowed FT Functions
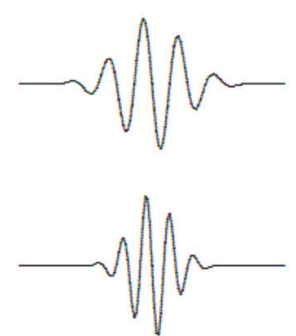

(c) Wavelets Transform Functions.

Figure 20: Comparison signals: Fourier transform and Wavelet transform [25].

The calculation of the wavelet coefficients in each possible scale generates a good amount of data. To minimize this task, only a subset of scales and positions are chosen. The chosen scales and positions are based on powers of two, called dyadic scales, which results in a much more efficient and fast analysis. This analysis is called the Discrete Wavelet Transform (DWT) [25].

For this purpose, the scale is defined as $a=2^{j}$ and the translation or displacement $b=k 2^{j}$ where $(j, k) \in Z$ and $Z$ is the conjunct of an integer number. Using in these parameters the DWT is defined as follow [28]:

$$
D W T_{j, k}=2^{-j / 2} \int_{-\infty}^{\infty} f(x) \psi\left(2^{-j} x-k\right) d x=\int_{-\infty}^{\infty} f(x) \psi_{j, k}(x) d x
$$

During the choice of the mother wavelet in the application of the DWT, approximately, one hundred functions were tested so that the best function for the identification of damages [10,29] could be selected. The selected functions are rbio2.6, bior6.8, sym6 and db5.

\section{Results}

\section{Case 1}

T n Fig. 21 the graphs of the data corresponding to the first frequency of the beam vs mass position is shown along the 26 nodes of the beam (discretization made at every $20 \mathrm{~cm}$ ). The added mass used was $3.266 \mathrm{~kg}$, positioned on each node. 


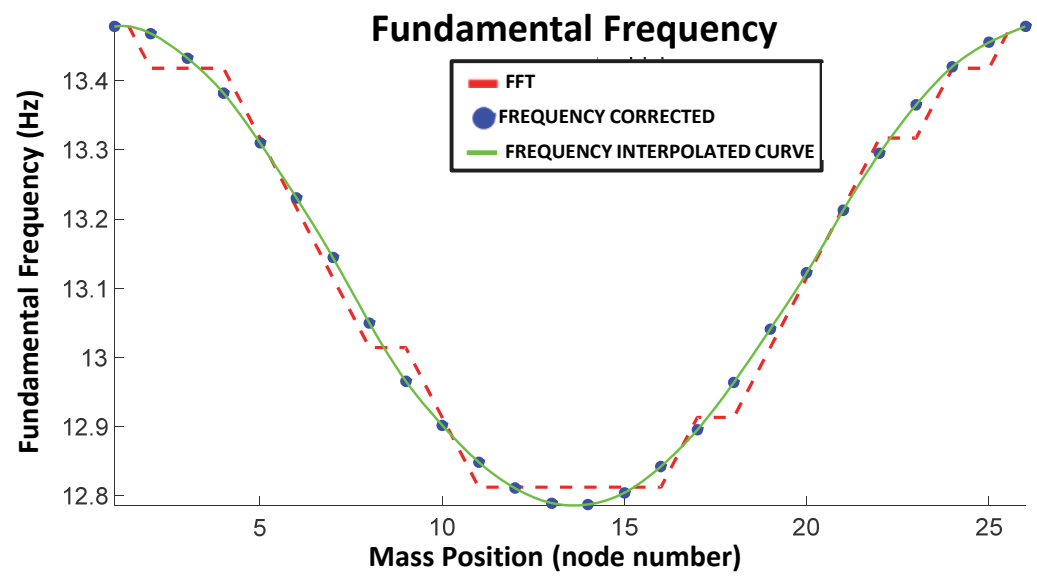

Figure 21: Mass (M) Position vs. First Frequency (f1).

In Fig. 21, the first graph (dashed line) represents the FFT peak frequencies; the second (dotted line) represents the corrected frequency using the FFT spectral lines around the peak as a weighted average to calculate the real frequency. The third curve (solid line) represents the interpolation of the corrected frequency (dotted line) by a cubic spline interpolation method which, according to Palechor. [29], is the method that best fits the signals used to locate damages in the steel beams.

Figs. 22 and 23 show the graphs corresponding to DWT applied to the previous signal considering the use of the four mother wavelet functions (rbio2.6, bior6.8, sym6, db5).

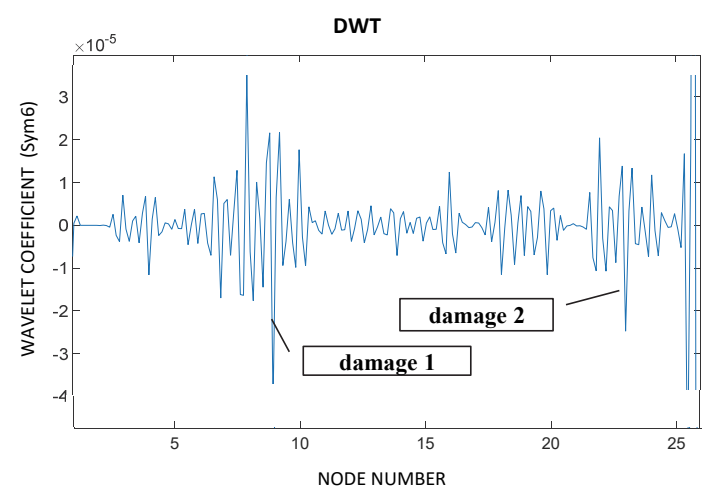

(a) Symlet 6

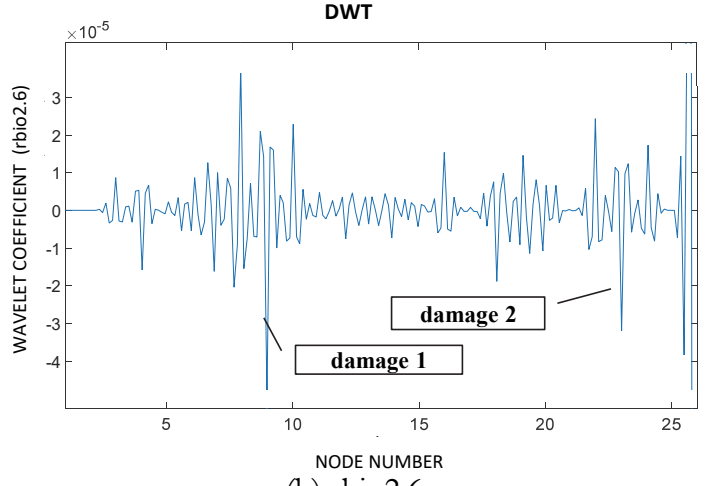

(b) rbio2.6

Figure 22: DWT First Frequency (f1) using Symlet 6 and rbio2.6 mother wavelets.

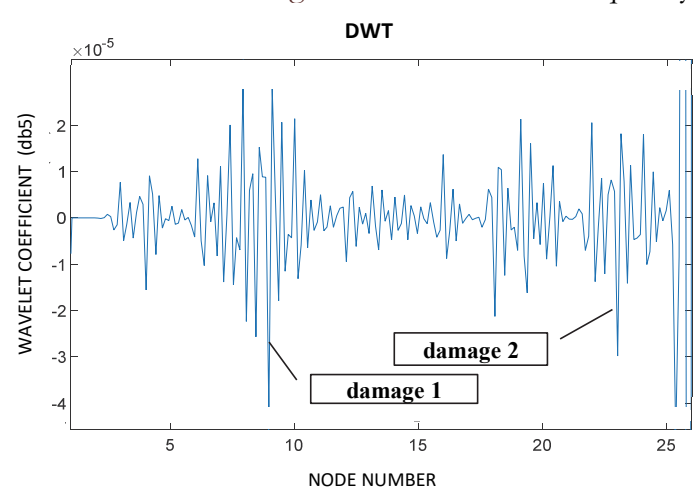

(a) db5

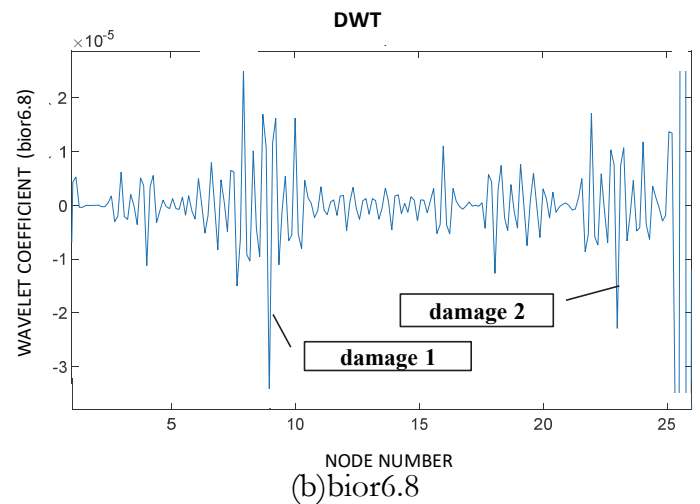

(b) bior6.8

Figure 23: DWT First Frequency (f1) using db5 and bior6.8 mother wavelets. 
In the previous figures (Figs. 22 and 23), it can be observed that the greatest peak, or spike, was generated between nodes 8 and 9 which matches to the damage located at $1.5 \mathrm{~m}$. The graph also shows a less prominent, but still noticeable, spike between nodes 23 and 24 which is the position of the second damage. Note that such peaks are big enough to be seen compared with the other peaks where no damage exists.

\section{Case 2}

In Fig. 24, the graph of the data corresponding to the first frequency of the beam vs. mass position is shown along 31 nodes of the beam (discretization made every $20 \mathrm{~cm}$ ). The added mass used was $24.718 \mathrm{~kg}$, positioned on each node location.

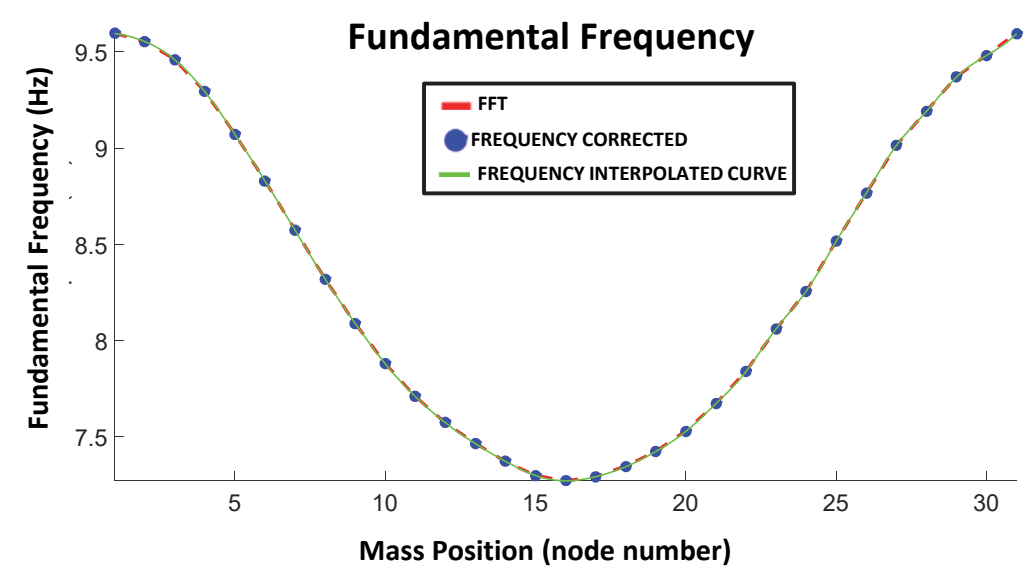

Figure 24: Mass (M) Position vs. First Frequency (f1).

In Fig. 24 three curves can be observed, the first (dashed line) represents the FFT peak frequencies; the second (dotted line) represents the corrected frequency using the FFT spectral lines around the peak as a weighted average to calculate the real frequency. The third curve (solid line) represents the interpolation of corrected frequency data (dotted line) by a cubic spline interpolation method.

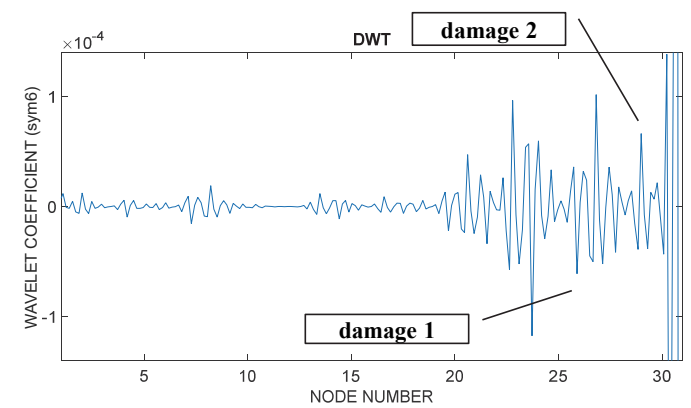

(a) Symlet 6 .

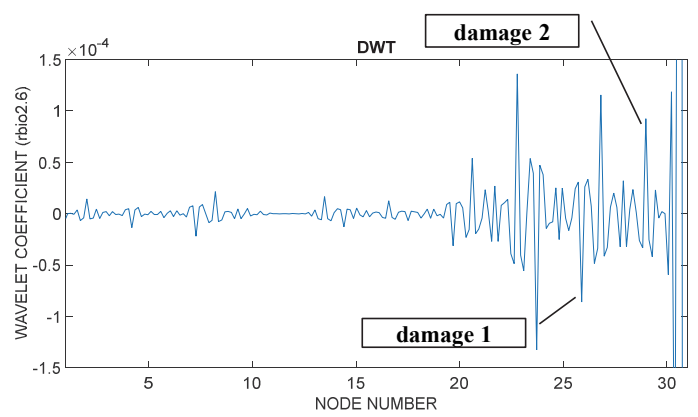

(b) rbio2.6.

Figure 25: DWT First Frequency (f1) using Symlet 6 and rbio2.6 mother wavelets.

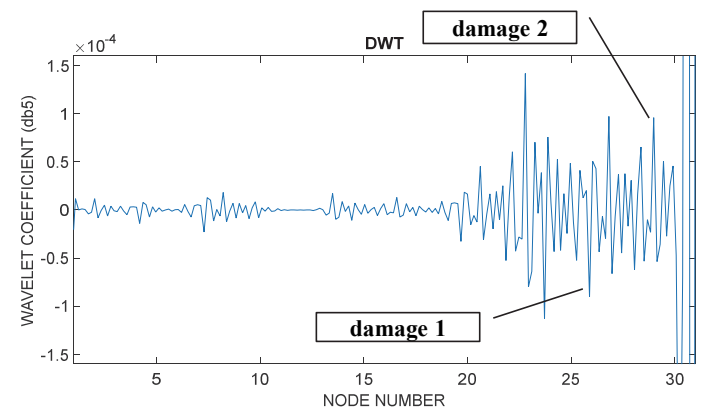

a) $\mathrm{db} 5$

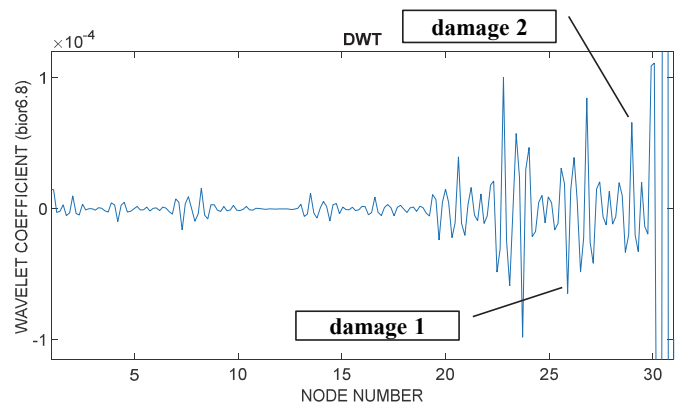

b) bior 6.8

Figure 26: DWT First Frequency (f1) using db5 6 and bior6.8 mother wavelets. 
Figs. 25 and 26 show the graphs corresponding to DWT applied to the signal in Fig. 24 and considering the use of the four mother wavelet functions (rbio2.6, bior6.8, sym6, db5).

In the previous figures (Figs. 25 and 26), it can be observed that the biggest peak was generated between nodes 24 and 29, matching the damage located in between nodes 26 and 28, corresponding to Damage- 1 and Damage-2, respectively. The techniques of signal interpolation with the cubic spline in the frequency domain and the method of main lobe correction showed good results.

\section{CONCLUSIONS}

$\mathrm{T}$ his research paper presented a new experimental methodology to locate damages in steel beams with simulated damages. The proposed methodology used just the measure of the fundamental frequency of a vibrating beam with an added mass positioned at different points along the beam. Two cases were analyzed in this research: Case- 1 and Case-2, respectively, with $5 \mathrm{~m}$ along and $6 \mathrm{~m}$ in Beam-1 and Beam-2 respectively, with $5 \mathrm{~m}$ and $6 \mathrm{~m}$ long. Both beams are steel I-section available in the market made of steel. Beam-1 was $5 \mathrm{~m}$ long and Beam-2 $6 \mathrm{~m}$ long. The damage can be detected observing the peaks of the Discrete Wavelet Transformation (DWT) of the signal representing the variation of the fundamental frequency vs. the Added Mass Positions (AMP). The method was tested with small and big simulated cracks. A set of one or more cracks was considered a damage and, in practice, it may be thought of as an equivalent deterioration of a beam cross section.

The best result was achieved in Case 1 of Beam-1 for the detection of the biggest damage which center is located at $1.5 \mathrm{~m}$ to the left end of Beam-1. This damage corresponds to a cluster of notches of $3 \mathrm{~mm}$ straight cuts made at the beam flanges and spaced $2.5 \mathrm{~cm}$ one each other. This damage can be seen in Fig. 2. Beam-1 was subdivided in 26 nodes, spacing between nodes equal to $20 \mathrm{~cm}$. The damages are located between nodes 8-9 and 23-24, respectively. Along those positions, the added mass was positioned. It was possible to clearly identify the damage using just the first frequency and the proposed methodology with an added mass of $3.266 \mathrm{~kg}$. The detection was possible observing the peaks signal of the first frequency vs. the added mass position; i.e., DWT-f1 vs. AMP curve. Such curve also shows noises of DWT-f1 signals at the extremes of Beam-1. These false peaks are noises due to the natural discontinuity of the beam at its ends.

Concerning smaller damages, the paper tested the proposed methodology for the detection of Damage-2. This damage corresponds to just one third of Damage-1. It was located also closed to a region showing noise signals, the region next to the right end of Beam-1. Again it was possible to detect the damage just observing the peaks of the curve DWT-f1 vs. AMP. For Case- 2 in Beam-2, two clusters of damages were located close to the supports of the beam. Beam-2 was subdivided in 31 nodes with the same space of $20 \mathrm{~cm}$ as used in Beam-1. Along those nodes the added mass was positioned. Damage-1 and Damage-2 were located, respectively and exactly, over node 26 and node 28. Such positions correspond, respectively, to $0.6 \mathrm{~m}$ and $1.0 \mathrm{~m}$ away from the right end of the beam. In Case-2, as in Case- 1 , the curves DWT- $\mathrm{f} 1 \mathrm{vs}$. AMP were built and the signal peaks observed. The added mass employed in Case- 2 was $24.718 \mathrm{~kg}$. The results showed peaks from node 21 to node 29, and big spikes next to the real positions of the simulated damages (Damage-1 and Damage-2). In Case-2, the locations of the Damage-1 and Damage-2, despite not being detected precise by as in Case-1, narrow down the spans one might be concerned to find damages. The experimental study shows it is possible to detect the exact damage position and the position near the damaged area using the proposed methodology. Therefore, with the proposed methodology it is possible to help to find the location of damages along steel beams just using the fundamental frequency of the damaged beams without the previous knowledge of the response of the undamaged structure.

\section{REFERENCES}

[1] Aktan A. E, Farhey D. N, Helmicki A. J. (1997). Structural Identification for Condition Assessment: Experimental Arts. Journal of Structural Engineering., 123, pp. 1674-1684. DOI:10.1061/(asce)0733-9445(1997)123:12(1674)

[2] Breysse D, Klysz G, Dérobert X, C. et al. (2008). How to combine several non-destructive techniques for a better assessment of concrete structures. Cement and Concrete Research., 38, pp. 783-793.

DOI:10.1016/j.cemconres.2008.01.016.

[3] Schabowicz K. (2010). State-of-the-art non-destructive methods for diagnostic testing of building structures anticipated development trends. Archives of Civil and Mechanical Engineering., 10, pp. 8-9.

DOI:10.1016/s1644-9665(12)60133-2 . 
[4] Radzieński M, Krawczuk M, Palacz M. (2011). Improvement of damage detection methods based on experimental modal parameters. Mechanical Systems and Signal Processing., 25, pp. 2169-2190. DOI:10.1016/j.ymssp.2011.01.007.

[5] Doebling S. W, Farrar C. R, Prime M. B. et al. (1996). Damage identification and health monitoring of structural and mechanical systems from changes in their vibration characteristics, California: Los Alamos National Laboratory, LA13070-MS.

[6] Wang, Q, Deng, X.M. (1999). Damage detection with spatial wavelets. International Journal of Solids and Structures., 36, pp. 3443-3468. DOI:10.1016/s0020-7683(98)00152-8.

[7] Law S.S, Li X. Y, Zhu X. Q. et al. (2005). Structural damage detection from wavelet packet sensitivity. Engineering Structures., 27, pp. 1339-1348. DOI:10.1016/j.engstruct.2005.03.014.

[8] Mikami S, Beskhyroun S, Oshima T. (2009). Wavelet packet based damage detection in beam-like structures without baseline modal parameters. Struct. and Infrastr. Eng., 7, pp. 211-227. DOI:10.1080/15732470802334795.

[9] Liu Y, Li Z, Zeng W. (2009). Crack detection of fibre reinforced composite beams based on continuous wavelet transform. Nondestructuive Testing and Evaluation., 25, pp. 25-44. DOI:10.1080/10589750902744992.

[10] Palechor E. U. L, Silva R. S. Y. C, Bezerra L. M, Bittencourt T. N. (2014). Damage Identification in Beams Using Experimental Data. Key Engineering Materials., 607, pp. 21-29. DOI:10.4028/www.scientific.net/KEM.607.21

[11] Ren W. X, Sun Z. S. (2008). Structural damage identification by using wavelet entropy. Engineering Structures., 30 , pp. 2840-2849. DOI:10.1016/j.engstruct.2008.03.013.

[12] Chen H, Lei W. L, Wei C., editors. (2011). Automatic correcting method of discrete spectrum with rectangular window. Proceedings of the 4th International Congress on Image an Signal Processing, Shangai (China). DOI:10.1109/cisp.2011.6100714.

[13] Ticona L. R, Silva R. S. Y. C, Bittencourt T. N. et al. (2016). Identification of Modal Parameters in a Scale Model for a Railway Bridge. International Journal of Structural Stability and Dynamics., 16, pp. 1-23. DOI: $10.1142 /$ S0219455415500595.

[14] Palechor E. U. L, Machado M. R, Morais M. V. G, Bezerra L. M, editors. (2017). Dynamic analysis of a beam with additional auxiliary mass spatial via spectral element method. Proceedings of the Dynamical Systems Theory and Applications DST, dec 11-14; lodz (Polonia).

[15] Vahit M. H. E. editors. (2001). Effect of Mass Attachment on the Free Vibration of Cracked Beam. Proceedings of the 8th International Congress on Sound and Vibration, Hong Kong (China).

[16] Kotambkar M. S. (2014). Mass Loading Effect on Natural Frequency of Cracked Beam in Free-Free Condition. International Journal of Engineering Research \& Technology., 3, pp. 113-120.

[17] Rizos P. F, Aspragathos N, Dimarogonas A. D. (1990). Identification of crack location and magnitude in a cantilever beam from the vibration modes. Journal of Sound and Vibration., 138, pp. 381-388. DOI:10.1016/0022-460x(90)90593-O

[18] Vakil B. M, Peimani M. (2008). Crack detection in beam-like structures using genetic algorithms. Applied Soft Computing., 8, pp. 1150-1160. DOI:10.1016/j.asoc.2007.10.003

[19] Bruel \& Kjaer. (1982). Measuring Vibration.

[20] Zhong S, Oyadiji S.O, Ding K. (2008). Response-only method for damage detection of beam-like structures using high accuracy frequencies with auxiliary mass spatial probing. Journal of Sound and Vibration., 311, pp. 1075-1099. DOI:10.1016/j.jsv.2007.10.004

[21] Ewins D. J. (2000). Modal Testing: Theory, Practice and Application, London (England): Imperial College of Science.

[22] Oppenheim A. V. (1999). Discrete-Time Signal Processing. Electronics and Power. University of Massachuset.

[23] Ge M, Lui E. M. (2005). Structural damage identification using system dynamic properties. Computers and Structures., 83, pp. 2185-2196. DOI:10.1016/j.compstruc.2005.05.002

[24] The Fundamentals of FFT-Based Signal Analysis and Measurement in LabVIEW and LabWindows/CVI - National Instruments. (2009).

[25] Ovanesova A. V. (2000). Applications of Wavelets to Crack Detection in Frame Structures [dissertation]. Puerto Rico. University of Puerto Rico.

[26] Wu N, Wang Q. (2001). Experimental studies on damage detection of beam structures with wavelet transform. International Journal of Engineering Science., 49, pp. 253-261. DOI:10.1016/j.ijengsci.2010.12.004

[27] Daubechies I. Ten Lectures on Wavelets. (1992). Philadelphia (Pennsylvania): Rutgers University and AT\&T Bell Laboratories.

[28] Misiti M, Poggi J. (2001). Wavelet Toolbox For Use with MATLAB. Natick, Massachusetts.

[29] Palechor, E. U. L. (2013). Identificação de Danos em Vigas Metálicas Utilizando Wavelets e Dados Numéricos e Experimentais [dissertation]. Brasília (BR): University of Brasília. 